\title{
Measurement and Analysis of Urban Total Factor Energy Efficiency in China
}

\author{
Feifei $\mathrm{Lu}^{1, *}$, Yinling $\mathrm{Lu}^{2}$, and $\mathrm{Na} \mathrm{Lei}^{3}$ \\ ${ }^{1}$ Management Science and Engineering, Lanzhou University of Technology, 730000Lanzhou, China \\ ${ }^{2}$ Civil engineering, Xuchang City Planning and Design Institute, 461000Xuchang, China \\ ${ }^{3}$ Civil engineering, Lanzhou University of Technology, 730000Lanzhou, China
}

\begin{abstract}
The improvement of urban energy efficiency is of great significance to reduce carbon emissions and achieve China's goal of carbon peak in 2030. Taking 266 cities as the research objects, the energy efficiency of each city is measured by Super-SBM model. Then the energy efficiency is decomposed by Malmquist index. The results show that: In 2006, the number of cities in high-efficiency areas is small and high efficiency areas are mostly distributed in the northeast and southeast coastal areas. There was a phenomenon of low efficiency areas agglomeration. But in 2017, the number of high-efficiency cities increased significantly. The number of high-efficiency cities in Northeast China increased, the number of high-efficiency cities in Southeast coastal areas decreased, and the number of high-efficiency cities in Central China increased and showed a phenomenon of agglomeration of high-efficiency areas or relatively high efficiency areas. According to the decomposition of urban energy efficiency, technological progress is the main driving force for the improvement of energy efficiency, and the decline of technical efficiency inhibits the improvement of energy efficiency in various cities.
\end{abstract}

\section{Introduction}

The Third China Energy Industry Development Annual Conference released the Review Framework of China's Urban Energy Reform, which believes that cities are the main body of the world's energy consumption and the main body of the implementation of various national energy policies. Analysis at the provincial level in China is difficult to solve the problem of total energy consumption distribution, so it is necessary to refine the study at the city level [1]. Cities gather all kinds of economic, technical and human support needed by energy transformation, so the study of urban energy efficiency has an important impact on exploring the characteristics of regional economic development. Urban economic development cannot be separated from energy, but economic development and energy development have brought serious problems of environmental degradation and energy depletion. In order to reduce the impact of economic development on the environment, the government has strengthened environmental regulation, but a debate has emerged between "green paradox" and "forcing emission reduction". In the face of multiple pressures, the breakthrough to improve urban energy efficiency is to actively explore the path of high-quality urban development, predict the comprehensive competitiveness of the city, and promote the sustainable development of the city.

At present, research on urban energy efficiency has made some progress. The core idea of optimizing urban energy efficiency is to create as high effective output as possible with as little resource input as possible, while restraining undesired output [2-5]. Most literatures believe that there is significant spatial difference in energy efficiency in different regions.

Based on the above analysis, although many scholars have studied energy efficiency, there are few analyses on the spatio-temporal differences of energy efficiency at the national level. Therefore, 266 cities in China are selected as the research objects, and the Super-SBM model is used to measure the energy efficiency of each city. According to Jenks natural breakpoint classification method, different energy efficiency zones are divided, and energy efficiency is further decomposed by Malmquist index.

\section{Construction of urban EE model}

\subsection{Measurement model of urban energy efficiency in China}

Data Envelopment Analysis (DEA) model is used to construct a non-parametric "effective frontier" by using linear programming model, which is used to analysis the allocation of non-parametric technical efficiency of multiple inputs and outputs. DEA model does not need to set the weight, which can avoid the influence of subjective factors when establishing the production function. SuperSBM model uses the non-radial efficiency measurement method to avoid the problem of slack between input and 
output. At the same time, linear combination is used to replace the decision-making unit of efficiency evaluation. When the efficiency value of decision-making unit reaches 1 , further efficiency evaluation can still be carried out to realize the ranking of decision-making units. The formula of Super-SBM model is:

$$
\begin{gathered}
\min \theta=\frac{1+\frac{1}{m} \sum_{i=1}^{m} \frac{S_{i}^{-}}{X_{i 0}}}{1-\frac{1}{S} \sum_{r-1}^{s} \frac{S_{r}^{+}}{Y_{r 0}}} \\
\text { s.t. }\left\{\begin{array}{l}
X_{0} \geq \sum_{j=1}^{n} X_{i j} \lambda_{j}-S^{-}(j=1,2, \ldots, m) \\
Y_{0} \leq \sum_{j=1, \neq 0}^{\sum_{i j}, \neq 0} \lambda_{j}+S^{+}(r=1,2, \ldots, s) \\
\sum_{j=1}^{n} \lambda_{j}=1 ; \lambda_{j} \geq 0 ; \lambda, S^{-}, S^{+} \geq 0
\end{array}\right.
\end{gathered}
$$

In the formula, $\theta$ is the effect value, $m$ and $s$ are input and output, $S_{i}^{-}$and $S_{i}^{+}$are relaxation variables of input and output respectively, $\lambda$ and are weights.

\subsection{Establishment and explanation of China's urban energy efficiency measurement index system}

According to "China City Statistical Yearbook", the prefecture-level cities and above were selected as the research objects, and the discontinuous data samples were eliminated. After adjusting the caliber of the unified administrative region, 266 cities and above were finally selected as the research samples. The research period was 12 years of panel data from 2006 to 2017. The selected index data and sources of China's urban energy efficiency measurement and spatial econometric model are shown in Table 1.

The number of urban employees at the end of the year was used as the index of labor input. Capital stock as the substitution variable of capital input. The perpetual inventory method is used to measure the capital stock, and the adjustment is carried out based on 2005.Energy consumption data is easy to cause errors due to different statistical calibers, and energy consumption is mostly output in the form of electricity, so the whole society's electricity consumption is selected as the measurement index of energy input.

Table 1. Selection of indicators for measuring energy efficiency in Chinese cities and data description.

\begin{tabular}{|c|c|c|}
\hline & Indicators & Describe \\
\hline \multirow{4}{*}{ Input index } & Labor input & $\begin{array}{c}\text { Number of urban } \\
\text { employees at year-end }\end{array}$ \\
\cline { 2 - 3 } & $\begin{array}{c}\text { Capital } \\
\text { investment }\end{array}$ & $\begin{array}{c}\text { Capital stock (adjusted } \\
\text { for 2005) }\end{array}$ \\
\cline { 2 - 3 } & $\begin{array}{c}\text { The energy } \\
\text { input }\end{array}$ & $\begin{array}{c}\text { Electricity consumption } \\
\text { by the whole society }\end{array}$ \\
\hline
\end{tabular}

\begin{tabular}{|c|c|c|}
\hline $\begin{array}{c}\text { Expected } \\
\text { output index }\end{array}$ & $\begin{array}{c}\text { Economic } \\
\text { output }\end{array}$ & $\begin{array}{c}\text { GDP by City (adjusted } \\
\text { for 2005) }\end{array}$ \\
\hline \multirow{3}{*}{$\begin{array}{c}\text { Undesired } \\
\text { output } \\
\text { indicators }\end{array}$} & $\begin{array}{c}\text { Pollutant } \\
\text { output }\end{array}$ & $\begin{array}{c}\text { Industrial effluent } \\
\text { discharge }\end{array}$ \\
\cline { 3 - 3 } & & $\begin{array}{c}\text { Industrial sulphur } \\
\text { dioxide emissions }\end{array}$ \\
\cline { 3 - 3 } & & $\begin{array}{c}\text { Industrial soot } \\
\text { emissions }\end{array}$ \\
\hline
\end{tabular}

\subsection{Decomposition model of urban energy efficiency in China}

The urban energy efficiency is decomposed by the Malmquist index. The Malmquist index can be summarized into two aspects: one is the change of the technical efficiency of the evaluated unit in a period of time, the other is the change of the production technology of the evaluated unit itself. According to the decomposition method, the Malmquist index from period to period is decomposed as follows:

$$
M_{0}\left(x^{t+1}, y^{t+1}, x^{t}, y^{t}\right)=\sqrt{\frac{E^{t}\left(x^{t+1}, y^{t+1}\right)}{E^{t}\left(x^{t}, y^{t}\right)} \frac{E^{t+1}\left(x^{t+1}, y^{t+1}\right)}{E^{t+1}\left(x^{t}, y^{t}\right)}}
$$

The Malmquist index is further decomposed as follows:

$$
M_{0}=\text { pech } \times \operatorname{sech} \times \text { tech } c h
$$

Where, pech represents the change of pure technical efficiency, reflecting the problem of technological dynamism; sech represents the change of scale efficiency, reflecting the impact of scale change on productivity by comparing the scale efficiency of different periods on the same production front; tech ch represents the change of technological progress, mainly describing the impact of technological progress on total factor productivity.

\section{Empirical results and analysis}

\subsection{Analysis of China's urban energy efficiency measurement results}

Using DEA -- Solver Pro 5.0 to measure the energy efficiency of Chinese cities, the energy efficiency of each city from 2006 to 2017 can be obtained. In order to clearly express the distribution of energy efficiency, ArcGIS software is used. According to Jenks natural breakpoint classification method, 266 cities were divided into high efficiency area, high efficiency area, low efficiency area and low efficiency area. Due to space constraints, in order to further analyze the change of energy efficiency, the energy efficiency of each city in 2006 and 2017 is shown in Figure 1. 

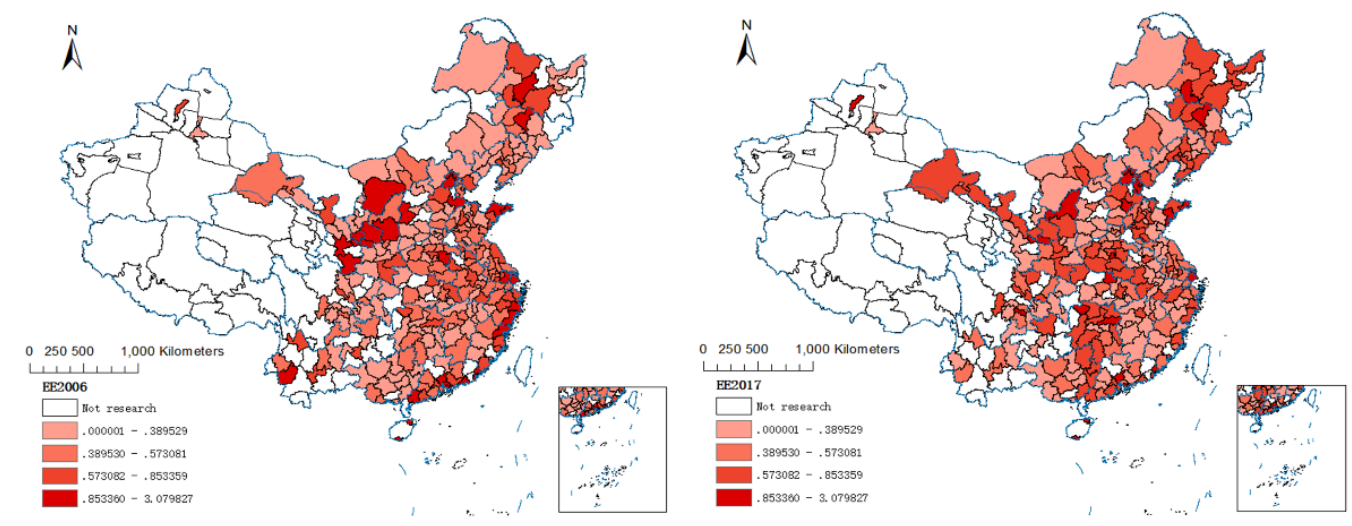

Fig. 1. Comparison of urban energy efficiency in 2006 and 2017.

As can be seen from Figure 1, in 2006, most of the high-efficiency areas were distributed in the northeast and southeast coastal areas. In the central region, except for some cities in the high-efficiency area and the highefficiency area, most of the provinces were in the lowefficiency area and the low-efficiency area. From the overall space, there was a phenomenon of agglomeration of low-efficiency areas. The number of cities with high efficiency in 2017 was significantly more than that in 2006. The number of cities with high efficiency in northeast China increased, but the number of cities with high efficiency in southeast coastal China decreased, and the number of cities with high efficiency in central China increased, showing the agglomeration of high efficiency areas or high efficiency areas. It shows that from 2006 to 2017, with the strengthening of environmental regulation, all cities in China can improve energy efficiency by accelerating green technology innovation, reducing environmental governance cost or improving energy technology. However, in the southeast coastal area, while promoting the rapid economic development, the pressure of energy use brought by a large number of population transfer and the problem of environmental pollution treatment may reduce the energy efficiency of the cities in this area.

\subsection{Decomposition of urban energy efficiency in China}

In order to further study the causes of energy efficiency changes, urban energy efficiency was decomposed from 2006 to 2017 through Malmquist index, and the results are shown in Table 2.

Table 2. Energy efficiency decomposition results of 266 cities in China.

\begin{tabular}{cccccc}
\hline Year & $\begin{array}{c}\text { Change of } \\
\text { technical } \\
\text { efficiency }\end{array}$ & $\begin{array}{c}\text { Change of } \\
\text { technological } \\
\text { progress }\end{array}$ & $\begin{array}{c}\text { Changes in pure } \\
\text { technical efficiency }\end{array}$ & $\begin{array}{c}\text { Scale efficiency } \\
\text { variation }\end{array}$ & $\begin{array}{c}\text { Energy } \\
\text { efficiency } \\
\text { variation }\end{array}$ \\
\hline $2006-2007$ & 1.035 & 1.03 & 1.028 & 1.006 & 1.066 \\
$2007-2008$ & 0.972 & 1.099 & 0.969 & 1.003 & 1.067 \\
$2008-2009$ & 1.029 & 1.028 & 1.047 & 0.983 & 1.058 \\
$2009-2010$ & 0.963 & 1.072 & 0.976 & 0.987 & 1.032 \\
$2010-2011$ & 1.101 & 0.808 & 1.080 & 1.019 & 0.889 \\
$2011-2012$ & 1.013 & 1.041 & 1.007 & 1.006 & 1.054 \\
$2012-2013$ & 1.039 & 0.938 & 1.022 & 1.016 & 0.974 \\
$2013-2014$ & 1.007 & 1.011 & 0.994 & 1.013 & 1.018 \\
$2014-2015$ & 0.966 & 1.062 & 0.978 & 0.987 & 1.026 \\
$2015-2016$ & 0.918 & 1.435 & 0.962 & 0.954 & 1.317 \\
$2016-2017$ & 0.901 & 0.977 & 0.903 & 0.998 & 0.881 \\
Mean & 0.995 & 1.046 & 0.997 & 0.997 & 1.035 \\
\hline
\end{tabular}

From Table 2, specific analysis shows that the technical efficiency can be decomposed into the product of pure technical efficiency and scale efficiency. From 2007 to 2008 , the technical efficiency declined, the change of pure technical efficiency was less than 1 , and the change of scale efficiency was greater than 1 . Therefore, the decline of pure technical efficiency during this period hindered the improvement of energy efficiency, indicating that the lack of technological development impetus in each city during this period was the reason for the decrease of energy efficiency. 2009-2010 and 2014-2017 technical efficiency drops, pure technical efficiency and scale efficiency changes are less than 1 , therefore during the pure technical efficiency and scale efficiency drops to hinder the improvement of energy efficiency, in the meantime the city failed to embody the effect of industrial structure optimization, to focus on industrial structure optimization of input-output efficiency. 


\section{Conclusions and policy recommendations}

(1) From time comparison, it can be seen that in 2006, most of the high efficiency areas were distributed in the northeast and southeast coastal areas, while most of the other provinces were in low efficiency and low efficiency areas, and there was a phenomenon of agglomeration of low efficiency areas. In 2017, the number of cities with high efficiency areas increased, and the central region showed the agglomeration phenomenon of high efficiency areas or high efficiency areas.

(2) From the decomposition of urban energy efficiency, it can be seen that technological progress is the main driving force of urban energy efficiency improvement, and the decline of technical efficiency inhibits the improvement of urban energy efficiency.

Therefore, the following suggestions are proposed. Promote regional coordinated development, and promote the overall energy efficiency of the central region in the way that high-efficiency zones drive surrounding areas. The southeast coastal areas should pay attention to the coordination and cooperation with the population policy and employment policy and give full play to the synergistic effect of the policies. Technological progress is the main driving force for energy efficiency, and technological innovation in energy utilization, pollution control and recycling should be strengthened.

\section{Reference}

1. M. Antonino, H. Lisanne, H. Oliver, F.Jimeno, G.Niki, R. Diana. RENEW SUST ENERG REV.124, (2020).

2. W. Guan, S. Xu. J. Geogr. Sci.06, 980-992 (2015).

3. Albrizio, S.,T. Kozluk, and Zipperer. J Environ Econ Manage81, 209-226, (2017).

4. Allen, F., J. Qian, and M. Qian. J financ econ77, 57116, (2005).

5. Betsill, M., and M. J. Hoffmann. REV POLICY RES.28,83-106, (2011). 